\title{
La Poesía de Eugenio Florit
}

W sentido de gran parte de la obra de Eugenio Florit es místico.

En tono callado, reservado, y muchas veces intencionalmente vago, exige mucho de la imaginación del lector. Al leerlo se siente que tiene pocos deseos de revelar demasiado sus sentimientos. Para mejor expresar su misticismo, su vaguedad y su reserva, usa en la mayor parte de sus poesías un tono surrealista.

\section{MISTICISMO}

E1 aspecto más importante que revela la poesía de Florit es su misticismo. En "Momento de cielo" se imagina asomado al cielo, completamente alejado de la tierra, libre de dolores y de risas, de todas las sensaciones humanas:

\footnotetext{
Delicia era

de saberse más alto que el dolor, puro sobre su cieno,

tranquilo ya sobre sus lágrimas, grande sobre su amor de tierra, firme sobre columna de aire y nubes.
}

"Momento de cielo" es uno de los poemas en que más usa los colores. Describe así el anochecer:

los azulados tintes y las sombras

como unos pensamientos sombríos de la luna...

Con su descripción de luces y sombras, nos da la impresión de que la tierra ya no tiene importancia para él, que es una cosa vaga, incierta, vista desde su altura: 
Pero desde él, desde la altura, la sombra de allá abajo parecía un color que se muda entre dos puntos, entre el ya y el aún. El impreciso resbalar de la laz por la penumbra.

En "Soledad" expresa otra vez esta idea de la irrealidad de la vida de aquí, de identificación con lo infinito:

en el cielo impasible miro pasar, extraña a la tierra, una nube con el color del alma. Para sentirme vivo echo al viento mi nombre.

Soledad a los vientos por regiones oscuras con la mirada ausente y una tímida angustia de asomarse a las aguas, y no ver mi figura $y$ atravesar las noches con el alma desnuda.

"Respuestas", publicado seis años más tarde, es del mismo tipo:

$-¿$ En qué piensa el poeta?

-Pienso en que estoy aqui, sobre la tierra ...

—¿Qué más?

-Que si la tierra fuera tan pequeña

que esta tarde cupiera

dentro del corazón...

- ¿Qué más?

-Que si pudiera

saber de qué color son los sueños...

$-i Y$ ?

-Y el árbol verde contra el cielo.

$Y$ la muerte, que huele a Primavera.

En "La niña nueva", mira a la niña y medita sobre los misterios de la vida :

Ya entre nosotros, forma verdadera, pequeña realidad de sangre viva, aún con el asombro, con la inquietud aún de no saber por qué llegaste...

Piensa en la imposibilidad de resolverlos:

Y no habrás de saberlo ya jamás aunque desplieguen a tu vista 
sus vuelos serafines,

y Dios se te revele en una rosa,

$y$ en una tarde el mundo se te entregue.

No lo sabrás. Y llorarás de pena,

y reirás, y tendrás el alma a flor de piel.

y amarás unos ojos,

y besarás labios de vida y muerte.

Pero no lo sabrás.

$\mathrm{Y}$ termina con una idea semejante a la de "Momento de cielo". Expresa su anhelo de morir, su convicción de que, como dijo otro poeta, William Wordsworth, our birth is but a sleep and a forgetting:

vivo

este sueño de ausencia atormentada

por volver a mi nube,

a $\mathrm{mi}$ rayo de luz,

a mi átomo de tierra:

a mi definitiva presencia entre la nada.

Hay algunos poemas en que, en lugar de generalizar sobre la muerte, el cielo, Dios, etc., lamenta la muerte de alguien a quien quería. "Las dos niñas" tiene un tono callado y resignado:

No, niña que preguntas, ya no quedan aquí los huesos de la niña muerta.

A'quí no hay más que tierra.

Aquí no hay más que un hombre y una fecha bajo el árbol y en medio de la yerba.

Aquí estamos tú y yo; tú con tus fresas que vas cogiendo, frescas.

y yo en mi soledad de siempre, mientras nos cae la lluvia de la primavera.

Pero Ella

ya no está aquí.

Con esas

alas de mariposa volandera

que se ponen los ángeles de veras,

se fué la recién hecha

a volar más allá de las estrellas,

a ser la luz pequeña

que en los ocasos su fulgor nos muestra,

a unir su voz de músicas aéreas

a la alta voz de la armonia eterna... 
Pero aquí,

aquí no hay más que tierra.

Tal vez, en el cajón de los recuetdos, sea su recuerdo uno de esos zapatitos de seda que se guardan dormidos, y que nadie despierta; tal vez la cabecita pasajera que se quedó un instante presa en la fotografía que ya se va poniendo amarillenta; y tal vez allá sea ese nombre que tú mitas suspensa bajo la tarde de esta primavera, aún más impreciso que en la piedra donde el amor de ayer grabó la fecha... Pero aquí donde estamos, nena, yo con mi soledad, tú con tus fresas, aquí no hay más que tierra, la única, la suficiente compañera.

No hay en ningún otro poema de Florit más pathos que en las referencias a los "zapatitos de seda" y a la "cabecita pasajera" de la fotografía.

El empleo de versos largos y cortos le da énfasis al contenido:

y yo en mi soledad de siempre, mientras

nos cae la lluvia de la primavera.

Pero Ella

ya no está aquí.

Y luego, otra vez, hay esa pausa después de los versos largos:

a la alta voz de la armonía eterna...

Pero aquí, aquí no hay más que tierra.

El efecto resignado de este poema se debe en gran parte a su ritmo lento y tranquilo. iQué distinto es este verso de un poema que analizaremos después!:

Grito ahogado de todos los siglos en un cráneo partido.

Después de leer "Las dos niñas" no se sorprende uno al descubrir que el autor sabe de memoria todos los nombres de los niños tallados en las losas del cementerio de Trinity Church, de Nueva York. 
Parece extraño - después de citar tantos ejemplos de un sentido místico, religioso- decir que a veces Florit se muestra casi ateo en su poesía. ¿Cómo se explica el contraste entre "La única":

Alli, yo sí la siento,

porque está donde el sol, brillante y pura:

en el punto feliz, riendo, llamándome;

con el abrazo abierto, siempre.

$Y$ he de ir hacia ella

-cada día más cerca, más seguro

de escuchar su canción, de ver su mano

llamándome, a la sombra de su risa.

(Donde desaparecen, en el mar, los navíos;

donde, en el cielo, desaparecen las palomas;

allí, sí, en aquel punto mudo de la tierra,

y allí, donde cayó desprendida una estrella.)

y la segunda canción de Reino?:

Bajo mis pies, la tierra, con sus senillas y sus huesos.

Grito ahogado de todos los siglos en un cráneo partido.

Grito ahogado de todos los hombres en la semilla deshecha.

Aqui, el ayer con su vendimia de muertes florecidas,

y el mañana con su promesa de raíces.

$Y$ aquí, sobre la tierra,

el hoy con la agonía de los brazos hundidos en el fango para buscar estrellas.

En "Canción para leer" hay la misma nota desesperada:

Luz, sí, luz hasta quebrarnos el alma al viento en mil gusanos de colores. Pero con ese fijo pensamiento de que mañana estará la luz sobre nosotros

[y ya no la veremos.

Hay algo en Florit que nos recuerda "La piedad que pasa" y otros poemas de Enrique González Martínez: una honda ternura, un amor para las pequeñas cosas de la naturaleza. En seguida se piensa en el mejor ejemplo, "A la mariposa muerta"; pero hay otro sin título, en Reino, que también merece ser citado:

No el miedo a tus noches, sendero, ni a tu horizonte lejano.

No el miedo a tus piedras ni a tu sol. 
No el miedo a las sombras de tus árboles secos, ni a tus nieves, ni a tus huracanes.

Sino el miedo a la flor que han de hollar mis pisadas cuando sea absoluto el silencio y pueda escucharse el ligeto crujir de sus pétalos.

II. COMPARACION ENTRE "DOBLE ACENTO" $Y$ "REINO"

TEMAS Y FORMAS

Lo primero que está escrito en Reino es:

Todo está dicho ya

$\mathrm{y}$ aún así hay que deçirio.

$\mathrm{Y}$ en efecto, en este libro Florit repite los temas del anterior, Doble acento. Las mismas imágenes - sueño, palomas, mariposasaparecen otra vez. Pero hay una diferencia importante en el estilo y en la forma, ambos menos complicados que antes. Juan Ramón Jiménez, en su prólogo a Doble acento, dijo:

Eugenio Florit, amigo mío hoy (por encima de la arteria) en llena y consciente belleza, funde dos líneas de la poesía española, la neta y la barroca, con un solo estilo igual o encadenado; lirismo recto y lento, que podría definirse "fijeza deleitable intelectual".

Aunque todavía en Reino queda la mezcla de los dos estilos, hay muchos poemas que son del estilo neto exclusivamente, sobre todo los poemas cortos. Sus imágenes y su lenguaje son más sencillos, y sus sentimientos más sinceros, que en los poemas anteriores:

Q Quién tuviera, como el río,

árboles para la sombra

y mar para su destino:

Emily Dickinson podría haber escrito lo siguiente:

IY que este llanto, el tuyo, el mío, el nuestro

no podamos secarlo con el mismo pañuelo!

Al leer éste y otros poemas cortos, me pregunto si no hay influencia de Emily Dickinson. No lo sé, pero sé que Florit ha expresado 
su "entusiasmo por los poetas ingleses y norteamericanos", y que ha hecho traducciones no publicadas.

Lástima que no use más estas formas cortas, porque son un buen medio para la expresión de sus sentimientos delicados y reservados.

Dos veces en Reino Florit repite una palabra o una frase a intervalos regulares, con efectos admirables, como en "Canción":

Suave, oloroso: espuma y ala:

amor.

Con brisa y sueño, y armonía: amor.

Alta canción, espejo límpido: amor.

Luna de plata o sol amigo:

amor.

Rudo, sin alma, abismo y sima: amor.

Con huracanes desvelados: amor.

Roto cantar, sollozo y queja; amor.

Noche sin luna, oscuro día: jamor:

\section{IMAGENES}

Al estudiar el estilo de Eugenio Florit, lo que más llama la atención es el uso repetido de ciertas palabras como símbolos, pero que cada vez pueden representar algo nuevo. Aun en un solo poema, una imagen - digamos una paloma, o una mariposa- puede aparecer en dos o tres versos distintos, con dos o tres interpretaciones. Por más que se lean algunas de estas imágenes, siempre guardan una sorpresa. Muchas son casi surrealistas, otras gongorinas, sibilinas. Pero hay otras menos difíciles, de cuya interpretación puede uno estar casi cierto.

Es sorprendente que un solo símbolo pueda querer decir tantas cosas para un autor, y que todas las interpretaciones de tal símbolo puedan ser tan ingeniosas y, al mismo tiempo, tan convenientes y bellas. La preponderancia de ciertas imágenes no quiere decir que el autor no pueda pensar en otras, porque hay muchísimas, muy bellas, que se usan una vez solamente, sin duda porque el poeta pre- 
fiere las otras. Al contrario, el poder de ver tanto en un solo símbolo muestra la riqueza de su imaginación poética.

\section{La paloma}

La paloma, por sus convencionales asociaciones religiosas, es un símbolo muy conveniente en el famoso "Martirio de San Sebastián". Simboliza, entre otras cosas, la paz que espera el mártir después de su muerte. Creo que este poema de Florit es el único en que la paloma se identifica con el sufrimiento. Es el instrumento del martirio del santo. San Sebastián piensa que su martirio es una cosa bella, gloriosa. La paloma, que es bella, presentada aquí como la causa del dolor, simboliza esta actitud típica del mártir. Tal efecto se aumenta con el uso del diminutivo:

Sí, venid a mis brazos, palomitas de hierro;

palomitas de hierro, a mi vientre desnudo...

y de esta descripción:

pequeñas querubines de alas tensas

y por el uso de la palabra caricia:

Qué dolor de caricias agudas.

En "La única”, la paloma parece tener una asociación mística con el cielo y la inmortalidad. El poeta piensa en una mujer que ha muerto. Ha de ir cada día más cerca de ella:

(Donde desaparecen, en el mar, los navíos;

donde, en e1 cielo, desaparecen las palomas;

allí, sí, en aquel punto mudo de la tierra,

y allí, donde cayó desprendida una estrella.)

A veces, como ya hemos dicho, en el mismo poema un símbolo tiene más de una significación. La paloma, símbolo convencional religioso, aquí representa "rezos mecánicos" para el muerto:

Aquí, en todo este cuerpo inmóvil caído sobre el lecho, cruce de suspiros y palomas de rezos mecánicos... 
La tercera línea del mismo poema es:

en la boca seca, que dejó escapar el pájaro de la palabra...

En las últimas dos líneas las palomas representan quizás las almas del muerto y de otro:

(Qué pena, señor, qué pena. Era tan joven.)

Allá lejos, se juntan dos palomas en vuelo.

Así se expresa la paz de la muerte en "Elegía para tu ausencia":

Te fuiste aquel minuto para toda la muerte a navegar en hondos océanos de silencio con un largo camino de pupilas dormidas y un bando de palomas prendido a tus ensueños.

Florit describe el "sentir que la vida se acaba" por el

Tibio tozar de palomas en vuelo...

En "Silencio", la paloma es la paz de la tarde:

Unas horas futuras

prontas a alzar el vuelo con las palomas de la tarde...

Dice de la estatua:

Tenías el ardor de las palomas de mármol en las fuentes del otoño,

y nos revela su blancura y su perfección de forma.

En "Nocturno", la paloma es el símbolo de la felicidad:

...tu felicidad de paloma en brazos de unos vientos sin rumbo...

Por lo general, la paloma simboliza la paz o la inocencia. Esto no es nada nuevo, pero las imágenes que usa Florit para representar la paz o la inocencia perdida son ingeniosas. En "Retrato", dice la mujer que acaba de describir:

Entre los dedos un alma de paloma muerta 
luchaba por entrarse hasta su sangre y anidar, otra vez, bajo su seno.

En "Canción" ("Tuviste que sacrificarme ..."), otra vez la paloma representa algo bello que se ha destruído o perdido - el amor, en este caso. Esta imagen es más fuerte que la otra:

Ya no sabes qué hacer con tu palabra de hielo prendida entre los labios, porque en la tarde miras la tristeza de una pobre paloma disecada.

2. Otras imágenes de aves y vuelo

Florit usa otras imágenes de aves:

el gris de las alondras de la mañana...

En "Casi soneto", otra vez asocia la alondra con la mañana en tna imagen contradictoria (porque ahora sugiere que el cielo es gris por falta de la alondra), pero igualmente linda:

Para ti, cielo gris de la mañana, vacío de la alondra y la amapola.

Es difícil saber precisamente qué representan las gaviotas en estas líneas, pero creo que simbolizan los pensamientos tristes del poeta:

Así veré, en la orilla de estos mares, para alegrat mis altas gaviotas, unas letras unidas al reflejo de su mirada.

Vemos aquí el motivo de letras y reflejos que se repite muchas veces, con unas variaciones, por ejemplo, en "Las dos niñas". Se habla del recuerdo de la niña muerta:

y tal vez allá șea ese nombre que tú miras suspensa bajo la tarde de esa primavera, aún más impreciso que en la piedra donde el amor de ayer grabó la fecha...

Compárese con estas líneas de "Elegía distante":

toda la noche cerca de una cruz sin historia con un nombre sencillo reflejado en el mar. 
En "La señal", la gaviota simboliza, no el pensamiento, sino el espíritu (o mejor dicho, el encanto) del mar:

Sobre la risa, that,

sobre las alegrías de colores,

sobre la estrofa azul y vetde

y sobre aquella cinta blanca;

sobre el fondo amarillo con sol de mediodía,

sobre la noche y sobre el gris cerrado bajo el cielo,

siempre la gaviota,

alta, y después baja, de nube al agua,

ala tendida y de caricia breve:

espiritu, señal graciosa del espíritu

sobre la risa abierta de la onda.

Las golondrinas representan inquietud en "Poema":

A cada amanecer pasaba sin razón la sombra inquieta de las golondrinas...

Se compara una canción con un águila herida y con un cisne de los crepúsculos sangrientos. Creo que la única referencia a un cisne está en "Casi soneto". ¿Por qué no hay más? En primer lugar, es el ave favorita de los modernistas, escuela a que Florit, naturalmente, no pertenece. Como no se interesa por temas clásicos o parnasianos, no es extraño que no se interese por el cisne, cuyas "credenciales", según Pedro Salinas, "consisten en haber amado a Leda y servido a Leonardo de modelo pictórico. En atraer caricias a la Pompadour en Versalles, en pasearse por el lago del romántico Luis de Baviera".

El cisne de Rubén Darío representa dos temas, el uno el "mito sensual" de Leda, pero éste es antipático al genio de Florit. El otro es "lo puro, ideal", que Florit sabe expresar con mayor originalidad por símbolos no tan gastados - estrellas, palomas, luz.

Hay, además de las imágenes de palomas, golondrinas, etc., muchas palabras como ala, aleteo, vuelo. Se habla de las plumas y las: alas del sueño. El poeta dice en "Aquarium":

Qué anhelo de volar sobre la espuma

de un libre mar, con horas libres...

y llama al mar:

pueblo de quillas y alas tensas. 
Dice de la armonía entre él y alguien a quien quiere:

¿Qué nido, al fin, para mi voz perdida!

(Nunca ya, el miedo oscuro

de esta palabra rota;

nunca, tampoco, el tímido aleteo

y después, iy después!, la hueca risa.)

Al final de Reino, agotada ya por un rato su inspiración poética, concluye :

Fija, aqui, la palabra:

ésa que nace ya sin alas;

esa tímida voz que no se exhala.

El poeta dice que antes de enamorarse:

el amor volaba intacto

como un halcón en acecho.

Después de enamorarse:

Qué piar de primaveras

bajo el alba de mi cielo.

El principio de la vida en el mundo, en "Poema cósmico", es:

el cruce de dos alas para el ensayo tímido del canto.

3. La mariposa

Uno de los más famosos poemas de Florit se titula "A la mariposa muerta":

Qué pequeña tu muerte bajo la luz de fuego vivo, qué serena la gracia de tus alas ya para siempre abiertas en el libro.

Lamentando que una mujer no le quiera, y preguntándose a quién quiere ella — dice que no sabe-, no sabe "qué mariposa vuela" en su pecho. 
Aqui, la mariposa es el beso del amante:

(Esta, sin duelo, alegre,

tiene a sus pies mi ensueño:

a su frente

mi atormentada mariposa) ...

$y$ en otro poema, la nieve

será un tropel de matiposas blancas

después, en el recuerdo...

Aquí la mariposa representa angustia:

Entre la espina del tecuerdo llega

a gritarme tu voz desesperada,

como una mariposa deshojada

bajo una pulsación de noche ciega.

Ahora la hermosura de la mariposa se identifica con el recuerdo de la muerta:

Como partiste en brazos del silencio apretado, resonará más viva la luz de tus palabras;

y en cada estrofa de aire se enredará un acento,

y en cada mariposa se nacerán más alas.

Por la fundición de dos sentidos en una sola imagen (resonará... la luz) y por el uso de sus palabras favoritas, "silencio", "mariposa" y "Iuz", esta estrofa es muy típica del estilo de Florit. La expresión "silencio apretado" merece ser repetida, y no es extraño que aparezca otra vez en "El momento callado":

$$
\begin{aligned}
& \text { y esta paz luminosa } \\
& \text { del silencio apretado... }
\end{aligned}
$$

Describe la belleza efímera de mayo como la hermosura "de mariposa incierta".

Aquí las mariposas se identifican con los rayos del sol:

Así te estás inmóvil a la orilla

de este sol que se fuga en mariposas. 
En "Poema", le recuerdan las manos de su novia; y

Con aquel palpitar de mariposas encendidas de ocaso, me suben desde el fondo del sueño tus manos con una

[esencia de violetas de nieve.

En "Las dos niñas", la muerte de una se describe así :

Con esas

alas de mariposa volandera

que se ponen los ángeles de veras,

se fué la recién hecha

a volar más allá de las estrellas...

El poeta dice en "Poema del fin" que cuando viene la muerte,

ya no sabrán qué rumbo han de tomar las mariposas.

4. El sueño

Florit escogió bien su "Preludio" a Reino:

El sueño ayer estaba tan cercano,

que se podian tocar las plumas de sus alas.

Tan cercano, que dejaba en el rostro su aliento

oloroso a violetas de nieve.

Tan cercano, que el corazón latía con el ritmo

con que latía el corazón del Sueño.

Sí, tan cercano el Sueño,

que sentía el calor de su sombra abrazada a mi cuerpo.

La palabra "sueño" tiene para Florit muchos significados. Cuando dice :

Cada día más lejos de mi sueño,

cada día más cetca

del único silencio,

es difícil saber si sueño quiere decir ilusión, deseo, o "el sueño de la vida". Quizás esta última interpretación sea la mejor, porque es claro que el "único silencio" es la muerte, y el autor pone al principio de otro poema la cita de Shelley, He is awakened from the dream of life. Además, esta interpretación parece ser la más conveniente 
para otros poemas en que usa la palabra sueño. Por ejemplo, en "Viejos versos de hoy":

y ya vivir es un sueño $\sin$ forma.

En "La nube", habla de "un sueño en agonía", cuando dice:

habré encontrado mi sueño para siempre.

Todo un sueño de siglos, de primaveras y de inviernos

que pasarán sobre mis huesos frios...

está usando la palabra como el símbolo de la muerte.

En "Aquarium" la usa para representar el encanto y el misterio del mar, lamentando la

abandonada concha, vacía de su sueño...

En "Canción", el sueño representa las ilusiones, los deseos, las esperanzas :

Ya sabiamos que arriba navegaba el sueño blanco en su barco de papel.

\section{El silencio}

Un motivo usado casi tanto como el del sueño es el del silencio, que en este poema es fuente de inspiración de pensamientos místicos:

Ahora, encerrado en un minuto de silencio, mejor aún: al regtesar de este minuto de silencio, puede contarse cómo corren los vientos sobre todos los mares y cómo suena la voz ya desnuda, y el aliento que vuela sin rumbo. Saber que el ayer está vivo junto al hoy y al mañana - tres hojitas de trébol en la nano dormida de Dios.Saber que la canción, puesta a volar sin destino seguro, aún agita sus alas por las esquinas abiertas del cielo,

y que todo el amor está de pie bajo la luz de las estrellas con el beso que huyó de unos labios en el suspiro último, y también, a dónde va el polvo de las mariposas, y en qué rincón del mundo se tiñen de azul los ojos de los ángeles.- 
El silencio se emplea aquí en una de las mejores metáforas de la muerte:

Déjame. Porque no tengo más amor dentro del pecho endurecido, que este amor a la tierra, o al mar, o a los vientos, o a las estrellas apagadas, adonde iré, cuando se pare el corazón y mis manos se caigan

[hacia el suelo para abrirse un pedazo de silencio.

\section{La estrella}

Las estrellas encarnan para Florit todo lo que es grande, bello, inalcanzable. Aqui representan la felicidad ya perdida, porque la mujer a quien ama el poeta se ha ido:

Eco de un sueño que en la noche busco

torciendo el hilo gris del pensamiento.

Es tarde ya para mirar estrellas,

y tengo frío.

En esta "Canción en la noche" simboliza desencanto:

¿Qué cerca, ayer, el cielo:

iba a tenerlo, aquí, en la mano!

I Iba a coger estrellas,

a estarme en éxtasis, adorando!

¿Qué lejos ya, qué muro de palabras,

entre ese cielo y yo, desesperado!

Piensa en la muerte, en la futilidad de tener fe en el futuro, o hallar la felicidad:

$Y$ aquí, sobre la tierra,

el hoy con la agonía de los brazos hundidos en el fango para buscar estrellas.

Se imagina en el cielo:

Estar asi, donde se juntan

los días y las noches.

Donde al pensar se encienden más estrellas.

Por el uso del adjetivo marchitas, da el doble efecto de una estrella y una flor:

estrellas de oro ya marchitas... 
7. $\operatorname{La} \ln z$

La luz es el espíritu de las cosas muertas, con el recuerdo de haber sido:

... el último trino de un pájaro y la última risa de los niños del parque.

Se usa la palabra "luz" en una descripción espléndida del relámpago:

$Y$ corre el ángel por veloz empeño de hundir lanzas de luz entre la tierra...

Aquí la "luz pequeña" es un alma. Cuando la niña muere, se va a volar más allá de las estrellas, a ser la luz pequeña, que en los ocasos su fulgor nos muestra...

La luz es también la vida en la tierra; ctuando viene la muerte toda esta luz, que ahora viaja de prisa en el aire, ya no tendrá vivas las alas, y dormirá suspensa y fría.

Quizás la luz aqui es la alegria:

se hace luz cuando calló la pena...

\section{La nieve}

En el poema "La nieve", el símbolo quiere decir dos cosas opuestas, alegría y tristeza. Es a la vez un símbolo abstracto y concreto:

Tú la verás, blanca y brillante, la tocarás, fría y suave.

Y estará junto a ti, sin angustiarte.

La tendrás en la mano, bajo el pie, frente a los ofos asombrados.

Te dolerá en la piel. Te hará reír de gozo.

La arrojarás al aire fino del invierno. Setá un tropel de matiposas blancas después, en el recuerdo. 
Pero no la tendrás eternamente

como yo, blanca y fría,

bajo el cielo feliz de los veranos.

En el "Preludio" a Reino, el sueño es "oloroso a violetas de nieve".

\section{El mar, único reflejo del ambiente}

La presencia del mar en la poesía de Florit es quizás el único reflejo del ambiente cubano. No es un poeta afroantillano, como Guillén o Pedroso, y 110 tiene dos estilos, como Emilio Ballagas, autor de "La elegía de María Belén Chacón" y "Elegía sin nombre". Su poesía casi nunca usa típicas palabras cubanas, ni siquiera los nombres tropicales más comunes. Una de las rarísimas excepciones es "A Juan Florit, Poeta, en Chile":

De aquí, de este punto de la tierra

tan distarite del tuyo, aunque lleve el apellido América.

De aquí digo, país de rumba y leche de cocoteros,

al umbral del horno en que se tuesta el mundo.

Aquí donde el mar es claro como mica encendida

y la noche tiene una voz más luminosa que el día.

10. El mar como tema principal

Uno de los más lindos entre los pocos poemas que tratan directamente del mar, es "La nereida muerta":

Comba del Mediodía sobre el thar de silencio. ¿Cómo fué la agonía. nereida, de tu muerte?

Padre Dios alza brazos sobre mudas arenas. por tocar deslizándose, un recuerdo sin alma.

Todo el Dios humillado por designio de luces llora espumas ardientes y suspiros de brisa. 
Y qué solas; al tiempo

de recordarte viva,

las ondas sin jinete

bajo el cielo se alargan.

IV. EL MAR EN LAS OBRAS DE TRES POETAS CUBANOS

\section{Florit}

El mar está casi siempre presente en la poesía cubana, pero no como personaje central, sino como elemento subconsciente, en muchas metáforas e imágenes. Florit es un ejemplo de esto. "La nereida muerta" es poema menos representativo de él que las citas siguientes, en que el mar es solamente parte de una descripción o de una metáfora:

El beso del Espíritu

le da una aureola tímida de perla

aún soñadora

con el silencio oscuro de los mares.

No quiere más que un canto

interminable y firme como el eco del mat.

$$
\begin{gathered}
\text { ("Retrato interior", } \\
\text { Cuatro poemas) }
\end{gathered}
$$

Como si todo junto de repente

se pusiera entre el hombre y su destino.

Como si ante el ocaso rojo abriera

un girasol sus rayos amarillos.

Como si aquella mano

de ayer regara azules lirios

y fuera el mar bajo la mano

un palomar de pétalos hetidos.

$\mathrm{Y}$ como si los barcos emergieran

de su muerte de hierros, de su sueño

de peces, de su olvido

para tender sus velas inmortales

a los vientos y al sol.

(Tarde presente",

Cuatro poemas) 
Cuando mi voz, sin cárcel, esté en la mariposa, y en la flor, y en trino, árbol, y espuma...

("Poema de mi voz", Reino)

Te fuiste aquel minuto para toda la muerte a navegat en hondos océanos de silencio.

("Elegía para tu ausencia", Doble acento)

Navego por las horas...

("Nocturno", Doble acento)

Suave, oloroso, espuma y ala:

amor.

$$
\text { ("Canción", Reino) }
$$

Y llora por amor, y luego ríe ese divino juego

de hojas al viento y llanto sobre el mat.

("Gloria de amor", Reino)

Fuego intimo de todos dos claveles despedazados, cortiendo a un mar sin forma, sin eco, sólo palabra.

\section{("Canción para leer", Doble acènto)}

Ya tu perfecta geometría sabe que es vano el aire y tímido el rocío; y como viene el mat sobre esa arena con el eco de tantos caracoles.

\section{("Estrofas a una estatua", Doble acento)}

A Diana :

No se olvida la fuente del vaporoso juego, el mat ya no se olvida de risas y canciones. Hay en la arena huellas de tu paso perdido, $y$ el aire, al recordarte, se detiene.

$$
\begin{aligned}
& \text { ("Nocturno", } \\
& \text { Doble acento) }
\end{aligned}
$$




\section{Julián del Casal}

Este mismo tratamiento del mar se observa en otros poetas cubanos, como Julián del Casal y José M. Heredia. El primero también lo incorpora en sus metáforas y sus descripciones, en vez de dirigirle largos apóstrofes:

Un bajel tuvo: la Fantasía;

$Y$ un mat espléndido: el mat del Arte.

("Flores de éter")

Desde lóbregos mares de sombras ven a calmar las ansias infinitas que como mat aitado impulsan el esquife de mi alma hacia país extraño.

\section{("Rimas")}

Como vientre rajado sangra el ocaso, manchando con sus chorros de sangre humeante de la celeste bóveda el azul raso, de la mat estañada la onda espejeante.

\section{("Crepuscular")}

Alli en un bando, humilde sacerdote devota sus pesares solitarios como el marino que en desierto islote echaton de la mat vientos contratios.

$$
\text { ("Las alamedas") }
$$

\section{José María Heredia}

Aun Heredia, el poeta cubano en quien hay más sentido del mar, lo muestra por lo general indirectamente. Con la excepción de poemas como "Calma en el mar":

E1 cielo está puro,

La noche tranquila,

I plácida reina

La calma en el mar, 
las referencias al mar se introducen casualmente. Llama a su esposa

Puerto de las borrascas de mi vida, Objeto de mi amor i mi tesoro...

$$
\text { ("A mi esposa en sus dias") }
$$

E1 mar aparece muchas veces en sus poesías patrióticas:

Si el despotismo

Al orbe abruma con su férreo cetro,

Será mi asilo el mar.

("Proyecto")

Su "Himno del desterrado" fué escrito en el mar:

Reina el sol i las olas serenas Corta en torno la prora triunfante.

I hondo rastro de espuma brillante

$V a$ dejando la nave en el mar.

iTietra! claman!...

El poeta pregunta en "Placeres de la melancolía":

¿Quién en adversa o próspera fortuna

No se abandona al vago pensamiento

Cuando suspira de la tierra el viento

I de Cuba en el mat duerme la luna?

\section{LA INFLUENCIA DE JOSE MARTI}

En un trabajo sobre Martí (Revista Iberoamericana, febrero de 1942), Florit cita varias estrofas del primer gran modernista, que rectierdan otras del mismo Florit. Después de leerlas, se siente que la delicadeza, la preocupación de la muerte y los "momentos de cielo" que caracterizan la obra de Florit, se deben en parte a su precursor. Hasta las imágenes son las mismas - mariposas, luz, estrellas, silencio, sueño:

Sobre la piel, curtida

de humanos aires,

matiposas inquietas

sus alas baten. 
De águilas diminutas

puéblase el aire:

iSon las ideas, que ascienden, rotas sus cárceles!

("Musa traviesa")

Que el balcón azotan

dos alitas blancas

que llenas de miedo

temblando me llaman.

("Tórtolas blancas")

... y no vuelan

del arbolar espeso entre las tamas

los pálidos espiritus amadós!

("Hierro")

De pie sobre las hojas amarillas.

en la mano fatal la flor del sueño,

la negra toca en alas rematada,

ávido el rostro, trémulo la miro

cada tarde aguardándome a mi puerta.

("Canto de otoño")

Yo, pálido de amor, de pie en las sombras, envuelto en gigantesca vestidura

de lumbre astral, en mi jardín, el cielo, un tamo haté magnifico de estrellas.

¡No temblará de asir la luz mi mano!

\section{("Flotes del cielo")}

El cielo, el cielo, con sus ojos de oro me mira, y ve mi cobardía, y lanza

mi cuerpo fugitivo por la sombra...

("Media noche")

$Y$ la tierra en silencio, $y$ una hermosa

voz de mi corazón, me contestaron.

("Homagno") 
... Se enciende como a fiesta, el aire claro

$y$ el vivo que a vivir no tuvo miedo,

se oye que un paso más sube en la sombra.

("Yugo y estrella")

Se podrían citar muchos versos más, pero éstos bastan para mostrar que hay un eco del acento martiano en la obra de Eugenio Florit.

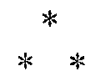

Al final del citado trabajo sobre Martí, Florit expresa sus teorías poéticas. "Lo importante — dice- es acumular recuerdos y horas intensas. Ese es nuestro tesoro." $Y$ luego este poeta místico, que gusta de preguntarse a dónde va el polvo de las mariposas, y en qué rincón del mundo se tiñen de azul los ojos de los ángeles, y de qué color son los sueños, expresa en los versos siguientes no sólo una teoría poética, sino una definición bella y exacta de su propia poesía. Sigue hablando de los recuerdos y horas intensas:

Quien no tenga de la tierra suya los tendrá en el cielo. Quien no de amor de mujer o de caricia de árbol, los tendrá de ala de sueño y viaje a nube y estrella.

\section{Esther ELISE SHULER,}

Instituto de Estudios Hispanoamericanos, University of Minnesota, Minneapolis. 